\title{
Modernisation Issues of Diesel-Electric Shunting Locomotive Power Units
}

\author{
Hardi Hoimoja, Tallinn University of Technology, Tanel Jalakas, Tallinn University of Technology, \\ Argo Rosin, Tallinn University of Technology, Anton Rassylkin, Tallinn University of Technology
}

\begin{abstract}
The research concentrates on the modernisation issues of inefficient diesel-electric shunting locomotives, produced in the former Soviet Union. The existing diesel-generator unit, serving as an onboard power plant can be replaced by hybridised units, with an energy storage unit acting as a peaking power source for dynamic modes. By integrating an energy storage unit into the power plant, the locomotive traction drive becomes hybridised, consuming less fuel during transients and idling.
\end{abstract}

Keywords: energy management, energy storage, rail transportation power systems.

\section{INTRODUCTION}

Diesel-electric transmission system in general means a transmission system, where the mechanical energy produced by the diesel engine prime mover is converted into electricity by means of a generator and transferred to an electric traction drive. The most frequent applications are diesel locomotives, marine vessels and mine trucks. In a strict meaning, a dieselelectric drive is an electric drive possessing its own power plant in the form of a diesel generator unit (DGU). The generated electricity is used for supplying the gearless traction drive and various auxiliaries, like lighting, battery charger, air compressor etc. The ample use of diesel-electric propulsion is based on the fact, that all internal combustion engines show optimal efficiency only in a very narrow speed range and cannot be started under load either. Therefore, in more powerful applications like locomotives, either diesel-hydraulic or diesel-electric transmission is preferred.

A major advantage of diesel-electric drives compared with diesel-hydraulic ones is a relatively simple and more reliable construction. The transmission can be controlled electrically, which means more soft acceleration and deceleration curves, essential for passenger traffic. Diesel-electric locomotives need no catenary, which makes them more popular and widespread than those fed directly from the overhead line. As a disadvantage, they must carry all energy conversion parts and resources like DGU and fuel tank on board.

A conventional diesel-electric propulsion system layout, used in the $1520 \mathrm{~mm}$ gauge railways is depicted in Fig. 1. The driver controls the power flow from the DGU to the wheels by selecting the position of the throttle handle. By throttling, the engine speed changes, the excitation current being controlled so, that the DGU output power is kept constant at all throttle

The study was supported by Estonian Ministry of Education and Research (Grant No B613A and BF124). positions, called notches. At constant power, the velocity can change only with the tractive resistance.

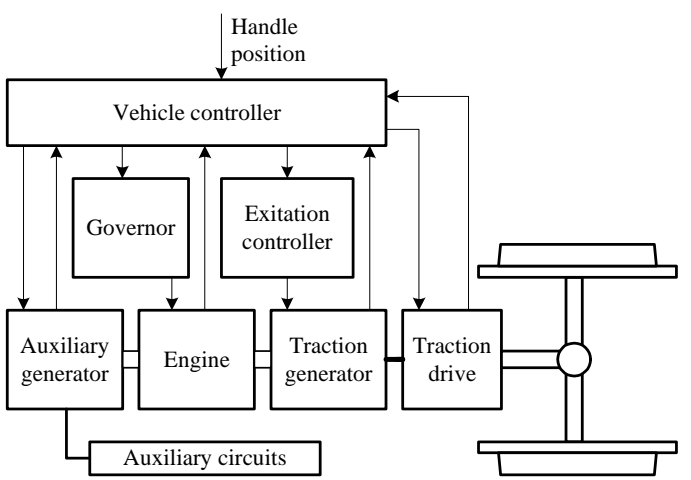

Fig. 1. A typical diesel-electric propulsion system layout

Whereas the diesel-electric powertrains still used on the $1520 \mathrm{~mm}$ gauge railways predominantly utilise the architecture with DC generators and DC series excited traction motors, the modern systems are based on the AC generators and $\mathrm{AC}$ variable frequency traction drives with common $\mathrm{DC}$ link, which are more efficient and reliable in operation.

\section{LOCOMOTIVE CLASSIFICATION}

There are two main types of locomotives, distinguished by their main working modes and load cycles:

1) mainline locomotives;

2) shunting locomotives.

The mainline locomotives operate on longer railway lines and show a familiar load and velocity diagram with acceleration, cruising, coasting and braking stages.

The shunting locomotives operate predominantly in the railyards, composing the echelons to be later displaced by the mainline locomotives. They are exposed to harsher loads with frequent peaks, i.e. accelerations and decelerations; the average power is several times smaller than the rated one. The main shunting locomotive types, used in the $1520 \mathrm{~mm}$ gauge railways and based on the DC architecture shown in Fig. 1 are listed in Table 1.

TABLE 1. MAIN SHUNTING LOCOMOTIVE TYPES USED IN 1520 MM GAUGE

\begin{tabular}{|l|l|l|l|}
\hline $\begin{array}{l}\text { Type } \\
\text { designation }\end{array}$ & $\begin{array}{l}\text { Engine power } \\
{[\mathrm{kW}]}\end{array}$ & $\begin{array}{l}\text { Main generator } \\
\text { power }[\mathrm{kW}]\end{array}$ & $\begin{array}{l}\text { Production } \\
\text { years }\end{array}$ \\
\hline TEM2 & 882 & 780 & $1960-1984$ \\
\hline TEM18 & 882 & 840 & $1992-\ldots$ \\
\hline ChME3 & 993 & 885 & $1963-1991$ \\
\hline
\end{tabular}


The varying load of shunting locomotives complicates the design of DGUs. Firstly, they must be able to deliver the full power during pulling the wagons; secondly, they must remain efficient during idling, when the power is delivered solely to the auxiliaries [1]. Namely the last issue has raised many questions, while the pressure related to the fuel prices and environmental requirements is constantly rising. Thus, the main research must be focused on how to make a locomotive power plant effective both for pulling and idling modes, with minimal fuel consumption and environmental stress. The research conducted so far is described in the next sections.

\section{LOAD CHARACTERISTICS OF A SHUNTING LOCOMOTIVE}

As stated in the previous section, the power unit of a shunting locomotive is exposed to greatly varying loads. In Fig. 2, a sample of TEM18 locomotive DGU output power during shunting operations in an oil shale railyard is presented. The DGU rarely reaches its rated power $840 \mathrm{~kW}$, operating mostly at underload or even idling. The same locomotive is used as an example in further calculations.

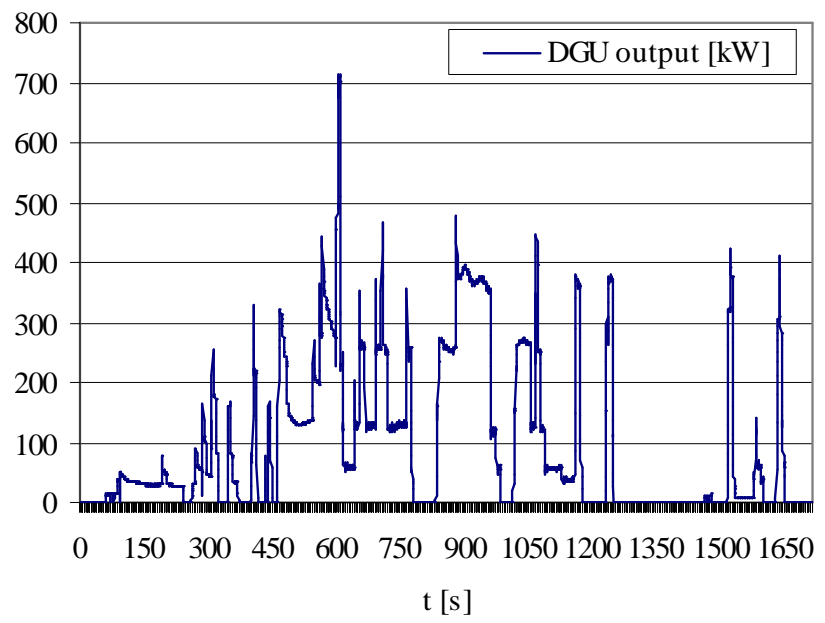

Fig. 2. A sample of DGU output power during shunting operations

The data samples were recorded by a Graphtec GL200 data logger with $0.5 \mathrm{~s}$ intervals. A more descriptive distribution of DGU load can be given by a histogram (Fig. 3). It becomes clear, that for approximately $80 \%$ of the cases, the load is $30 \%$ or less of the rated output. Thus the DGU is not fully utilised, making its operation inefficient.

The efficiency of a diesel engine, expressed by fuel consumption per produced mechanical energy, depends on its load and rotational speed. The modern DGUs' specific fuel consumption in optimal region is $190 \mathrm{~g} / \mathrm{kW} \cdot \mathrm{h}$, which can grow to $220 \mathrm{~g} / \mathrm{kW} \cdot \mathrm{h}$ while operating at loads below $0.3 \mathrm{p}$.u. Though the difference might seem negligible, the locomotives operating at $24 / 7$ basis make the difference tangible. To maintain the efficiency by smaller loads, the engine must slow down. This however is not possible in a wider scale because the engine's construction limits the possible speed range. Thus other measures must be taken to improve power unit's efficiency, like hybridisation by means of additional energy storage units.

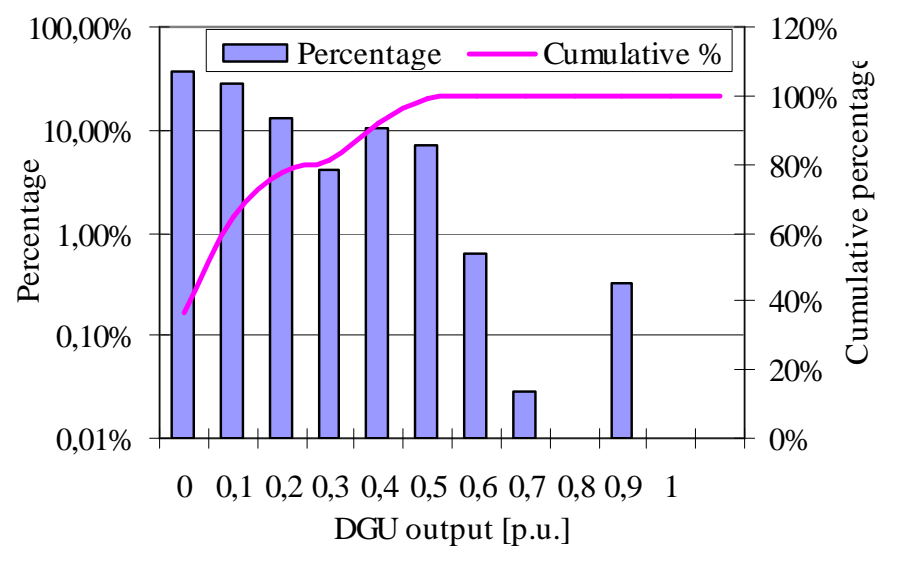

Fig. 3. Power histogram of a TEM18 DGU during shunting

\section{HYBRIDISATION OF THE POWERTRAIN}

Hybrid electric vehicles utilise power from more than one energy source, most frequently a heat engine and an energy storage unit (ESU). Two main types of hybrid powertrains are: 1) series hybrid;

2) parallel hybrid.

While modernising the diesel electric locomotives, the series hybrid topology should be preferred, where the prime mover is not directly linked to the transmission for mechanical tractive power [1]. Rather, all of the energy produced from the engine is converted to electricity by the generator which recharges the ESU in order to provide power to one or more electric motors. The vehicle is propelled solely by electric motor system. Because the heat engine is not directly connected to the wheels, it can operate at a more optimum rate and can be switched off for temporary all-electric, zeroemission operation [2]. A series hybrid powertrain layout, suitable for a locomotive, is shown in Fig. 4.

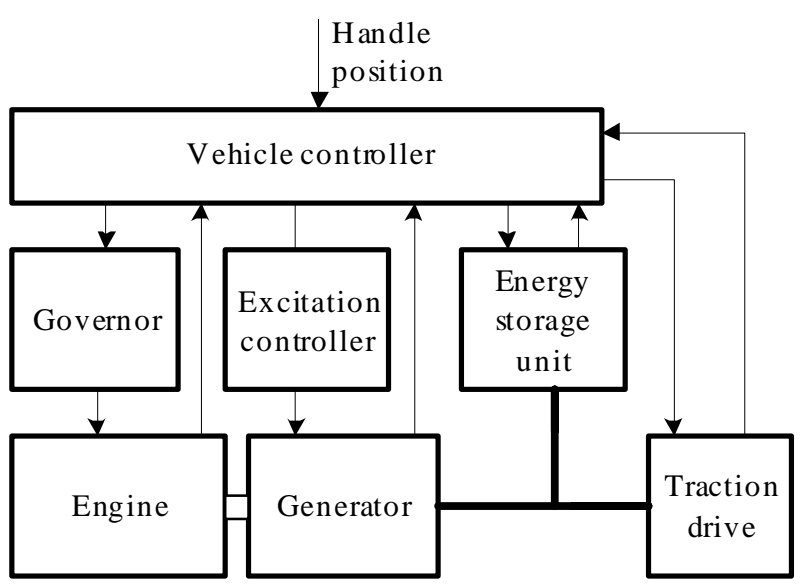

Fig. 4. Series hybrid locomotive powertrain layout

The vehicle controller must co-ordinate the load distribution between the main generator and the ESU, keeping its state-ofcharge (SOC) in admissible window. If the traction drive allows regeneration, the ESU can store the braking energy for later use, thus providing even more fuel efficiency. 


\section{A. ESU parameter calculations}

The ESU, integrated into the series hybrid power drive, acts as a low-pass filter suppressing peak loads, which in signal processing theory can be characterised as high-frequency noise. In discrete form, a first-order low-pass filter can be expressed by the recurrence function [3]

$$
P_{D G U, k}=\frac{\tau}{\tau+\Delta t} \cdot P_{D G U, k-1}+\frac{\Delta t}{\tau+\Delta t} \cdot P_{L, k}
$$

where $P_{L}$ is the filter input or non-stabilised load value, $\tau$ the filtering time constant representing ESU capacity/power ratio, $P_{D G U}$ is the filter output power corresponding to the instantaneous sum of load and storage powers, i.e. the resulting supply power from the DGU and $\Delta t \rightarrow 0$ is the finite time step, i.e. the sampling interval of the load power. The first right member of the (1) represents the so-called inertia from the previous filter output (DGU power) and the second member is the contribution of the instantaneous input value (load power). The longer the time constant, the less is the DGU power influenced by the load fluctuations. Obviously, with no storage, $P_{D G U}=P_{L}$.

An example, explaining the effect of an ESU on the DGU output power diagram, is shown in Fig. 5. It becomes evident, that the bigger the time constant $\tau$ and resultantly the ESU capacity and power, the more effectively are the load fluctuations dampened (compare with Fig. 2).

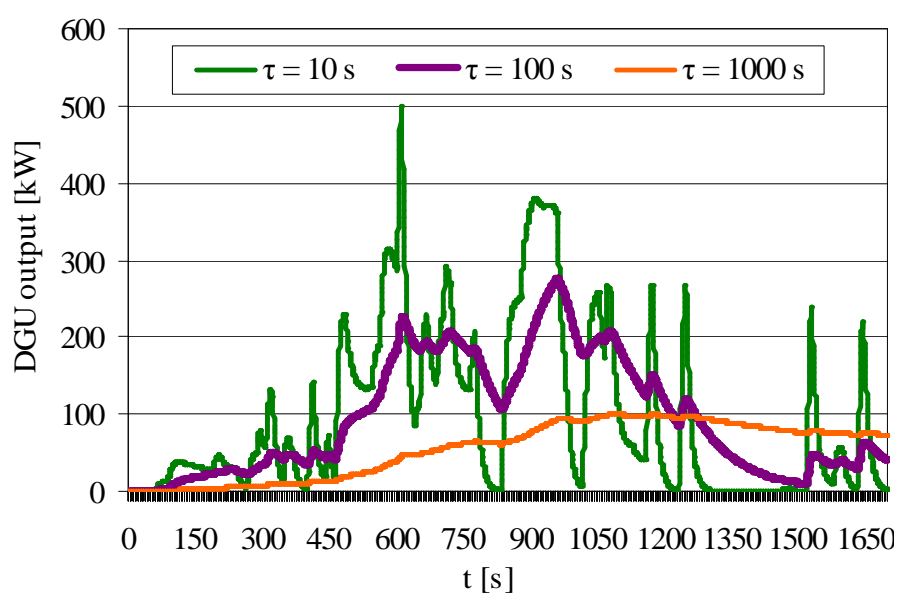

Fig. 5. Effect on ESU filtering time constant on the DGU output power

By subtracting the DGU power $P_{D G U}$ from load the power $P_{L}$, the ESU output power at time step $k$ is obtained

$$
P_{E S U, k}=P_{L, k}-P_{D G U, k}
$$

For calculations, all the samples must be read into a multidimensional array with $k$ rows for further processing. The energy drawn from the storage at time step $k$ is described in a discrete form by

$$
W_{E S U, k}=-\Delta t \cdot \sum_{m=1}^{k} P_{E S U, m}
$$

After that, the energy amount for levelling the fluctuations can be found from [3]

$$
W_{E S U}=\max _{k=1 \ldots n} W_{E S U, k}-\min _{k=1 \ldots n} W_{E S U, k}
$$

where $n$ is the total number of data samples. The necessary storage power [3]

$$
P_{E S U}=\max _{k=1 \ldots n} P_{E S U, k}
$$

With an ESU, the DGU maximum output power diminishes remarkably, as shown in Table 2. Accordingly, the primary power source can be selected smaller, more energy efficient and environmental friendly. The results obtained at different time constant values can be interpolated and the dependency between the DGU and ESU scalings constructed, as depicted in Fig. 6.

TABLE 2. ESU DIMENSIONING BASED ON TIME CONSTANT T

\begin{tabular}{|l|l|l|l|}
\hline$\tau[\mathrm{s}]$ & $\mathrm{W}_{\mathrm{ESU}}[\mathrm{MJ}]$ & $\mathrm{P}_{\mathrm{ESU}}[\mathrm{kW}]$ & $\mathrm{P}_{\mathrm{DGU}}[\mathrm{kW}]$ \\
\hline 10 & 5.02 & 335 & 501 \\
\hline 100 & 27.7 & 510 & 277 \\
\hline 1000 & 100 & 671 & 100 \\
\hline
\end{tabular}

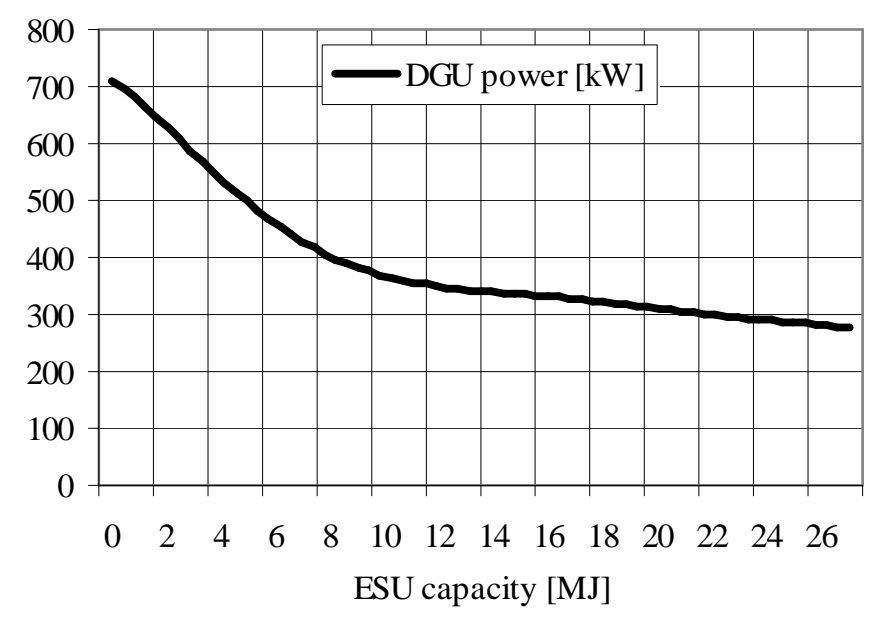

Fig. 6. DGU output vs ESU capacity

\section{B. Technology selection}

However, the DGU downscaling has its limits, caused by the dimensions and costs of the ESU. The general criteria while selecting an energy storage unit are as follows [5]:

1. The effective capacity and power must respond to the given task.

2. The onboard space for an ESU is limited.

3. The onboard installation must not negatively influence the vehicle's performance.

4. The vehicle's construction must withstand the additional mechanical load caused by the storage unit.

5. The installed energy storage unit must have an acceptable pay-back period. 
From the space and weight limitations it may be concluded that the energy storage technologies applicable for electric traction must have good gravimetric and volumetric power characteristics, i.e. as much delivered power per mass and volume unit as possible. Such characteristics are common to storage mediums like double-layer capacitors (DLC) and flywheels $(\mathrm{FW})$. The necessary mass $m_{S M}$ and volume $V_{S M}$ for the storage medium of an ESU can be found from

$$
\left\{\begin{array}{l}
m_{S M}=\max \left(\frac{W_{E S U}}{w_{m, S M}} ; \frac{P_{E S U}}{p_{m, S M}}\right) \\
V_{S M}=\max \left(\frac{W_{E S U}}{w_{V, S M}} ; \frac{P_{E S U}}{p_{V, S M}}\right)
\end{array}\right.
$$

where $w_{m, S M}, w_{V, S M}$ are the gravimetric and volumetric energies and $p_{m, S M}, p_{V, S M}$ gravimetric and volumetric powers of the storage medium, respectively.

To decrease the observed DGU peak load by half, an ESU with $P_{E S U}=450 \mathrm{~kW}$ and $W_{E S U}=12 \mathrm{MJ}$ should be selected (Table 2, Fig. 6). The storage medium masses for the most common technologies are shown in Table 3.

TABLE 3. STORAGE MEDIUM MASSES FOR A $12 \mathrm{MJ}, 450 \mathrm{KW}$ ESU

\begin{tabular}{|l|l|l|}
\hline Storage medium & $m_{S M}[\mathrm{~kg}]$ & $V_{S M}\left[\mathrm{~m}^{3}\right]$ \\
\hline Lead-acid battery & 4500 & 12 \\
\hline DLC & 750 & 0.9 \\
\hline FW & 600 & 1.0 \\
\hline
\end{tabular}

The mass and volume of the lead-acid battery storage medium is determined rather by their gravimetric power rather than the energy, opposite may be stated of DLC and FW. From the listed storage mediums, double-layer capacitors, also referred to as super- or ultracapacitors are of state-of-the-art [1] [4]. For the next, DLC-based ESU integration possibilities into a locomotive powertrain are explained.

\section{DLC and powertrain interconnections}

Two DLC integration possibilities into the diesel-electric powertrain exist [6]:

1) series cascaded structure;

2) parallel structure.

The main difference between those two interconnections is the application of interface power converters.

In the series architecture (Fig. 7), the DLC battery terminal voltage is also the input voltage for the traction drive. The converter enables a precise control of the DGU output, making it independent on the load imposed on the traction drive. To crank the engine while operating the generator as a starter motor, the DGU converter can be designed bidirectional. If the traction drive has regenerative braking capabilities, the DLC battery, acting as a passive filter can also absorb braking energy. The converter must commutate only DGU power, which is less in amplitude and fluctuations than the load. The major disadvantage of the series cascaded architecture is the varying voltage on the traction drive input terminals. To some extent, this problem may be solved with parallel-series switchover of DLC groups inside the battery [7].

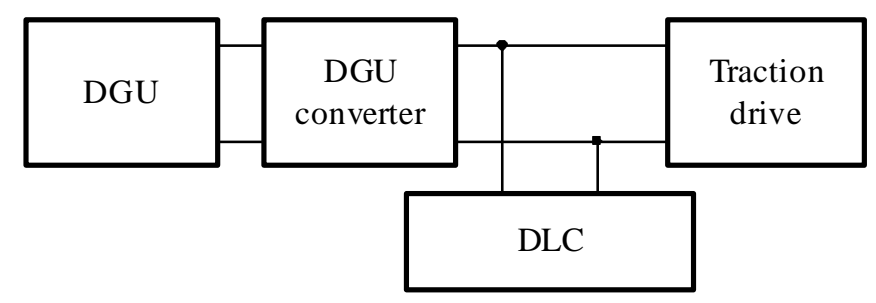

Fig. 7. Series cascaded powertrain architecture

In parallel structure (Fig. 8), the DLC battery is connected to the powertrain via an interface converter, which together comprise the ESU assembly. Like in the series cascaded solution, the DLC battery can be charged either from the DGU or from the traction drive in the regenerative braking mode. Here the ESU acts as a fast active filter, compensating load fluctuations by injecting or absorbing controlled energy to or from the powertrain. By applying buck-boost converters as the DLC power interface, the traction drive input voltage can be kept nearly constant. The DGU converter matches the DGU output with the common DC link voltage and limits the inrush current of capacitive circuits; it can as well be used for cranking the engine. A disadvantage of the parallel architecture is the existence of an additional converter, which must be powerful enough to inject dynamic power into the locomotive powertrain.

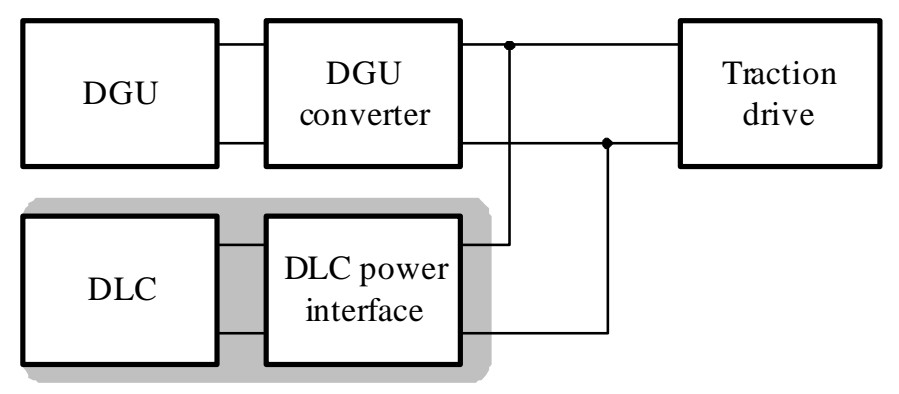

Fig. 8. Parallel powertrain architecture

Parallel architecture prevails in implementations thanks to the better and more controlled use of the energy stored in the DLC battery. Namely, the effective energy exchange is considered to be between $(0.5 \ldots 1.0) \cdot U_{D L C}$, where $U_{D L C}$ is the rated voltage of a DLC battery. Thanks to the buck-boost interface converter, the DC link voltage is independent on the DLC terminal voltage, which is determined by its SOC.

\section{DGU modernisation}

The existing powertrain of the locomotives described in Table 1 is fully DC-based with rotary amplifiers. Apart from being morally outdated, such a solution is characterised by poor efficiency and high maintenance costs due to the extensive mechanical wear of rotating parts and the brushes. A state-of-the-art approach necessitates the application of brushless synchronous generators (alternators), with the AC 
output to be matched to the DC link voltage by the means of rectifiers, either controlled or uncontrolled [8].

To select an appropriate generation set, some requirements must be defined beforehand:

1. The common DC link voltage between the DGU converter, ESU terminals and traction drive input must be kept nearly constant.

2. To endow the locomotive the additional functionality of an emergency mobile power plant, the DGU must be able to provide constant $50 \mathrm{~Hz}$ output frequency for standard three-phase $400 \mathrm{~V} / 230 \mathrm{~V}$ applications.

The last requirement states the engine-alternator set must operate at constant speed with the constant output voltage. Thus conventional sets might be applied, which show acceptable specific fuel consumption between $50 \% \ldots 100 \%$ of the rated load. In Table 4, the data of a commercial DGU suitable for the hybrid powertrain are shown.

TABLE 4. SELECTED DGU DATA

\begin{tabular}{|l|l|l|l|}
\hline & DGU assembly & Engine & Alternator \\
\hline Type designation & V440C2 & TAD1242GE & LS 472VS3 \\
\hline Manufacturer & SDMO & Volvo-Penta & Leroy-Somer \\
\hline $\begin{array}{l}\text { Rated power } \\
(\cos \varphi=1)\end{array}$ & $365 \mathrm{~kW}$ & $387 \mathrm{~kW}$ & $365 \mathrm{~kW}$ \\
\hline Rated voltage & & & $400 \mathrm{~V} / 230 \mathrm{~V}$ \\
\hline Rated frequency & & & $50 \mathrm{~Hz}$ \\
\hline
\end{tabular}

In the existing powertrain, the DGU power is controlled directly by the driver changing the throttle and the excitation current (Fig. 1). With the new solution, the output power is controlled indirectly. The control handle is reconnected to the traction drive, whereas the engine tries to sustain its speed and accordingly the generator output frequency and voltage by fuel injection and excitation control, which is implemented by a downstream digital throttle controller.

\section{E. DGU converter}

The DGU three-phase AC output must be matched to the DC link voltage. This is done by using AC/DC converters like:

1) diode rectifiers;

2) thyristor rectifiers;

3) PWM IGBT rectifiers.

Diode rectifiers are the cheapest and simplest options of voltage matching. Their $\cos \varphi \approx 1$, therefore they draw only active power from the DGU. The resulting DC link voltage of a six-pulse bridge rectifier

$$
U_{D C}=1.35 \cdot U_{L-L},
$$

where $U_{L-L}$ is the line-to-line alternator output voltage. The rectified DC link voltage of the generator described in Table 4 calculated after (7) becomes $540 \mathrm{~V}$, which is sufficient for supplying a locomotive traction drive.

A drawback of the diode rectifiers is the uncontrolled energy flow, which complicates the pre-charging of capacitive filter circuits. The use of current limiting resistors is related to additional losses, the electromechanical shunting contacts reduce the overall reliability as well. Therefore thyristor rectifiers could be a choice, while by controlling the firing angle, soft charging of the filter circuits, and by forced commutation, fast-acting protection can be implemented.

Reversible PWM rectifiers allow the soft pre-charging of the filter circuits as well. During dynamic braking of the locomotive when the traction drive feeds the DC link, the torque drag of the idling engine can be overcome by the alternator working as a motor fed from the DC link, simultaneously shutting off fuel injection. The alternator could also function as the engine starter [8][8].

\section{F. DLC selection}

A DLC battery is composed of a number of series and parallel connected DLC cells. The total capacitance $C_{\Sigma}$ of the DLC battery can be derived from the necessary capacitance, rated voltage $U_{E S U, N}$ and the $S O C$ window $S O C_{\max } \ldots S O C_{\min }$. If a buck-boost converter is used as a power interface, then $S O C_{\text {max }}=1, S O C_{\min }=0.5$, and the total capacitance is expressed by

$$
C_{\Sigma}=\frac{2 \cdot W_{E S U}}{0.75 \cdot U_{D L C, N}^{2}},
$$

where $U_{D L C, N}$ is the rated terminal voltage of the battery. If $U_{D L C, N}=U_{D C}=540 \mathrm{~V}$, then the total capacitance for the observed storage medium after (8) would be $110 \mathrm{~F}$.

For the next, the DLC battery dimensions must be found, i.e. the number of capacitors in series connections $n_{s}$ and the number of parallel strings $n_{p}$. The number of series capacitors can be calculated by dividing the battery terminal voltage $U_{D L C, N}$ with the single cell voltage $U_{C, N}$ and rounding the result to the ceiling value

$$
n_{s}=\left\|\frac{U_{D L C, N}}{U_{C, N}}\right\|
$$

As the usual value for $U_{C, N}=2.7 \mathrm{~V}$, then $n_{s}=200$. The number of parallel strings can be calculated from

$$
n_{p}=\left\|\frac{C_{\Sigma}}{C_{C}} \cdot n_{s}\right\|
$$

where $C_{C}$ is the capacitance of a single DLC cell. If the DLC battery is assembled from BCAP3000 P270 cells (manufactured by Maxwell) with $C_{C}=3000 \mathrm{~F}$, then $n_{p}=8$. The total number of cells in a DLC battery

$$
n_{\Sigma}=n_{s} \cdot n_{p}
$$

which in given example means $\mathrm{n}_{\Sigma}=1600$.

Rounding the results to the ceiling value means slight overdimensioning of the storage medium, which compensates the errors made during idealising the circuits. 


\section{G. Auxiliary supply upgrades}

At present, the supply of the DC auxiliaries ( $74 \mathrm{~V}$ for the TEM2 and TEM18 locomotives, $110 \mathrm{~V}$ for the ChME3) is provided by a special rotary converter on the common shaft with the DGU. The use of a common DC link enables to replace the rotary converter with a DC/DC static one, like applied in the light rail vehicles [9]. These converters are based on the intermediate AC-link technology, which can be either one- or three-phase. Such converters are comprised of an input filter, a medium-frequency inverter, an isolating transformer and a rectifier. Additional auxiliary inverters may be used for supplying AC auxiliaries, such as compressors, presently driven mechanically by the engine main shaft.

\section{PROPOSED POWER PLANT LAYOUT}

To resume the previous sections, a novel power plant layout for a diesel electric hybrid shunting locomotive is proposed (Fig. 9). The engine is now controlled indirectly so, that it is optimally utilised together with the alternator and the ESU. This layout is independent on the traction drive type, which can be either based on chopper-controlled DC motors or inverter-fed induction motors. The auxiliaries are connected to the common DC link over a designated converter.

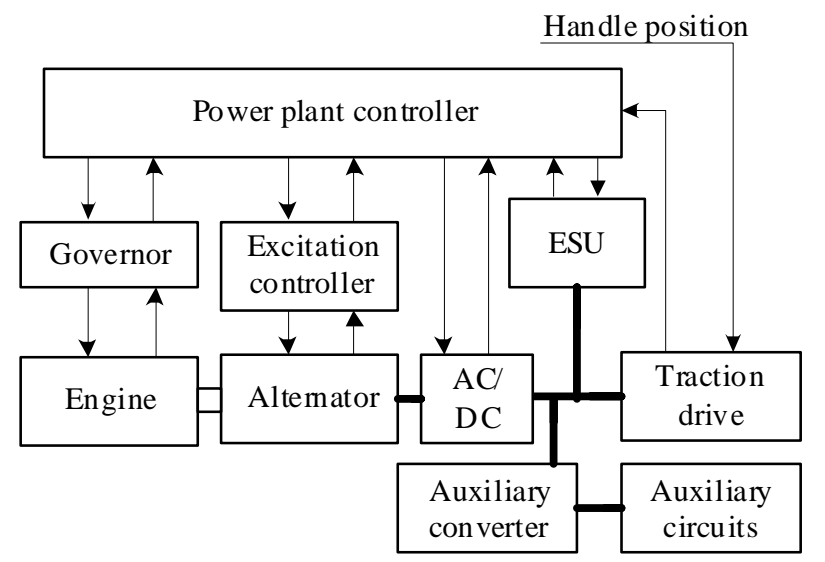

Fig. 9. Proposed layout for a modernised TEM18 onboard power plant

\section{CONCLUSIONS}

1. In the presented paper, modernisation of the diesel-electric locomotive power plants was discussed. The main conclusions that can be drawn as follows:

2. The existing diesel generator units are poorly utilised, mostly operating below the optimal specific fuel consumption region.

3. The diesel generator units can be downsized several times if hybridised power plants are used; the limits are set only by the cost and space constraints. The hybridisation yields in significant fuel economy.

4. The influence and parameters of an energy storage unit in the hybrid locomotive powertrain can be calculated using discrete low-pass filter analogy.

5. The outdated DC technology should be replaced with more reliable AC systems with a common DC link, more reliable in operation. The diesel generator units with fixed output voltage and frequency can be applied as emergency mobile power plants or for powering other rolling stock.

6. The auxiliary generator should be replaced by a static converter, more reliable in operation.

\section{REFERENCES}

[1] B. Destraz, P. Barrade, A. Rufer, "Power Assistance for Diesel-Electic Locomotives with Supercapacitive Energy Storage," Proc. of the 35th Annual IEEE Power Electronics Specialists Conference, 2004, pp 677682.

[2] P. A. Flaherty, "Multi-Stage Hybrid Drives For Traction Applications," Proc. of the ASME/IEEE 2005 Joint Rail Conference, March 15-18, 2005, pp. 171-175.

[3] J.V. Paatero, P.D. Lund, "Effect on Energy Storage on Variations in Wind Power," Wind Energy, Volume 8, Issue 4, 10/2005, pp. 421-441.

[4] J. Cheng, J. Mierlo et al., "Super Capacitor based Energy Storage as Peak Power Unit in the Applications of Hybrid Electric Vehicles," Proc. of the 3rd IET International Conference on Power Electronics, Machines and Drives, Mar 2006, pp. 404-408.

[5] Y. Zhao, J. Yao, Z. Zhong, Z. Sun, "The Research of Powertrain for SuperCapacitor-based Series Hybrid Bus," Proc. of the IEEE Vehicle Power and Propulsion Conference, Sept. 3-5, 2008, 4 p.

[6] A. di Napoli, F.G. Capponi, L. Solero, "Power Converter Arrangements with Ultracapacitors for Battery Load Leveling in EV Motor Drives," Proc. of the 8th European Conference on Power Electronics and Applications, Sept 7-9, 1999, 8p.

[7] E. Takahara, T. Waaksa, J. Yamada, "A Study for Electric Double Layer Capacitor (EDLC) Application to Railway Traction Energy Saving including Change Over between Series and Parallel Modes," Proc. of the Power Conversion Conference, Vol. 2, April 2-5, 2002, pp. 855-860.

[8] O. Koerner, J. Brand, K. Rechenberg, „Energy Efficient Drive System for a Diesel Electric Shunting Locomotive," Proc. of the 11th European Conference on Power Electronics and Applications, September 11-14, $2005,10 \mathrm{p}$.

[9] D. Vinnikov, "Isolated DC/DC Converter Topology with a Three-Phase Intermediate AC-Link," Proc. of the 10th International Baltic Electronics Conference, Oct 2-4, 2006, pp 1-4.

Hardi Hõimoja received the Dipl.Eng degree in electrical engineering from Tallinn University of Technology, Tallinn, Estonia, in 1998. At the end of 2009 he defended the $\mathrm{PhD}$ thesis devoted to energy efficiency estimation and energy storage calculation methods for traction applications. At the present time he is a researcher in the Department of Electrical Drives and Power Electronics. He has over 20 publications and owns a utility model in the field of electrical drives and power electronics.

Tanel Jalakas received the B.S. degree from Tallinn University of Technology, Tallinn, in 2003 and the M.Sc. Tallinn University of Technology in 2006. In 2010, he defended his Ph.D. thesis on the research and development of high-power high-voltage DC/DC converters. Since 2002, he has been working in the Department of Electrical Drives and Power Electronics of Tallinn University of Technology, Tallinn, Estonia, where he is now a researcher. His fields of interest include DC-DC high voltage converters and traction converters for electric rail vehicles. He is an author or co-author of more than 30 publications and owns 4 utility models in his research field.

Argo Rosin received the Dipl.Eng, M.Sc. and Dr.Sc.techn. degrees in electrical engineering from Tallinn University of Technology, Tallinn, Estonia, in 1996, 1998 and 2005, respectively. He is presently a Senior Researcher in the Department of Electrical Drives and Power Electronics, Tallinn University of Technology. He has published more than 40 papers on energy management, control and diagnostic systems development and is the holder of a patent in this application field. His research interests include modelling and simulation of power management and industrial control systems. He is member of Estonian Association of Engineers, Estonian Association of Transport and Roads.

Anton Rassylkin received the B.S. and M.S. degrees in electric drives and power electronics from Tallinn University of Technology, Tallinn, Estonia, in 2008 and 2010, respectively. His main scientific interests lay in the energyefficient industrial robotics and electric transportation. He has also worked for the ABB Robotics GmbH in Friedberg, Germany. Since 2010, he is a PhD student at the Tallinn University of Technology. 